\title{
Activation of pregnane $X$ receptor inhibits experimental dermal fibrosis
}

\author{
Christian Beyer, ${ }^{1}$ Alla Skapenko, ${ }^{2}$ Alfiya Distler, ${ }^{1}$ Clara Dees, ${ }^{1}$ Helena Reichert, ${ }^{1}$ \\ Louis Munoz, ${ }^{1}$ Jan Leipe, ${ }^{2}$ Hendrik Schulze-Koops, ${ }^{2}$ Oliver Distler, ${ }^{3}$ Georg Schett, ${ }^{1}$ \\ Jörg H W Distler ${ }^{1}$
}

\begin{abstract}
- Additional material is published online only. To view please visit the journal online (http://dx.doi.org/10.1136/ annrheumdis-2012-202476).

1 Department of Internal Medicine 3 and Institute for Clinical Immunology, University of Erlangen-Nuremberg, Erlangen, Germany ${ }^{2}$ Division of Rheumatology, Medizinische Klinik und Poliklinik IV, University of Munich, Munich, Germany ${ }^{3}$ Department of Rheumatology, University Hospital Zurich, Zurich, Switzerland
\end{abstract}

\section{Correspondence to} Dr Jörg H W Distler, Department of Medicine 3 and Institute for Clinical Immunology, University of Erlangen-Nuremberg, Ulmenweg 18, Erlangen D-91054, Germany; Joerg. distler@uk-erlangen.de

Received 8 August 2012 Revised 7 November 2012 Accepted 2 December 2012 Published Online First 5 January 2013

\section{ABSTRACT}

Objective To assess the antifibrotic effects of pregnane $X$ receptors (PXRs) in experimental dermal fibrosis. Methods The antifibrotic effects of PXR activation by

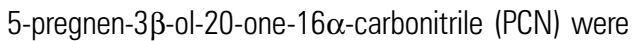
studied in the bleomycin model for prevention of dermal fibrosis and the modified bleomycin model for the treatment of established bleomycin-induced dermal fibrosis. Activation of canonical transforming growth factor (TGF) $\beta$ signalling was analysed by immunofluorescence staining for phosphorylated smads. The antifibrotic effects of PXR activation were further studied in murine fibroblasts and murine T cells under Th2 conditions. In the T cell experiments, synthesis of the profibrotic cytokines, interleukin (IL)-4 and IL-13, was assessed by quantitative PCR, and IL-13 levels in the murine skin were determined by multiplex bead array technology.

Results Activation of PXR effectively inhibited the development of bleomycin-induced dermal fibrosis and induced the regression of established dermal fibrosis as assessed by skin thickening, hydroxyproline content and myofibroblasts. Reduced levels of phosphorylated smad2 and smad3 suggested that the antifibrotic effects of PXRs were mediated by inhibition of canonical TGF $\beta$ signalling. While PXR activation appeared to have no direct effects on fibroblasts, it potently inhibited the release of the profibrotic cytokine, IL-13, from Th2 cells. Consistent with these findings, IL-13 levels were reduced in bleomycin-challenged murine skin upon PXR activation. Conclusions Our findings demonstrate a novel antifibrotic role for PXRs in inflammatory dermal fibrosis. The antifibrotic effects of PXRs appear to be indirect: PXR activation reduces the release of the Th2 cytokine, IL-13, from T cells resulting in decreased canonical TGF $\beta$ signalling.

\section{INTRODUCTION}

Fibrosis arises from excessive deposition of extracellular matrix components and results in scarring of various tissues. It is a hallmark of systemic sclerosis (SSc), which is a prototypical fibrotic disease affecting both the skin and many internal organs such as the lungs and gastrointestinal tract. ${ }^{1-3}$

Fibroblasts are the key players in the development of fibrosis. They show pathological and persistent activation, with enhanced expression of contractile proteins and excessive release of extracellular matrix components. Skin biopsy specimens taken early in the disease course of SSc reveal perivascular mononuclear infiltrates, with $\mathrm{T}$ cells representing the major inflammatory cell type. $\mathrm{T}$ cells, which show a $\mathrm{T}_{\mathrm{H} 2}$ phenotype in fibrotic disease, can activate fibroblasts and drive fibrosis by releasing profibrotic mediators, including the Th2 cytokines, interleukin (IL)-4 and IL-13. ${ }^{1-5}$

Pregnane-X-receptors (PXRs) belong to a superfamily of nuclear receptors that function as ligand-activated transcriptional regulators. PXRs are considered to be orphan nuclear receptors, as no endogenous ligand of PXRs has been identified to date. ${ }^{6}$ In the non-activated state, PXRs are located in the cytoplasm. Upon ligand binding, they enter the nucleus to regulate target gene transcription. PXRs are expressed in a variety of tissues and cells, including hepatocytes, enterocytes, monocytes and $\mathrm{T}$ cells. The physiological effects of PXRs are pleiotropic. Their role as a master regulator of endobiotic (eg, bile acids) and xenobiotic (eg, drugs) metabolism is well established. ${ }^{6}$ In addition, PXRs are involved in glucose and lipid regulation, since they inhibit hepatic gluconeogenesis by reducing $\beta$-oxidation and ketogenesis. ${ }^{6}$ Finally, recent studies suggest a role for PXRs in inflammatory conditions, since deregulated PXR activity has been implicated in the pathogenesis of inflammatory bowel disease, liver cirrhosis and cancer. $^{7-10}$

\section{MATERIALS AND METHODS}

Detailed information of the following methods are provided in the online supplementary data.

\section{Prevention and treatment of bleomycin-induced} skin fibrosis

Skin fibrosis was induced in DBA/2 mice (Janvier, Le Genest Saint Isle, France) by subcutaneous injections of bleomycin. $\mathrm{PCN}^{11}$ was dissolved in corn oil and applied intraperitoneally daily to a final dose of $25 \mathrm{mg} / \mathrm{kg}$, as described previously. ${ }^{12-16}$

\section{Immunofluorescence for p-smad2/3}

Formalin-fixed, paraffin-embedded dermal sections from murine skin were stained with antibodies against p-smad2/3 (Acris Antibodies, Herford, Germany) and anti-Alexa Fluor 594-tagged secondary antibody (Invitrogen, Carlsbad, California, USA). ${ }^{15}$

\section{T cell stimulation assays}

$\mathrm{CD} 4 \mathrm{~T}$ cells were isolated from the spleens of 6-week-old BALB/c mice using the Miltenyi mouse 
CD4 T cell Isolation Kit II (Miltenyi Biotec, Bergisch-Gladbach, Germany). CD4 $\mathrm{T}$ cells were incubated in anti-CD3 $(10 \mu \mathrm{g} /$ $\mathrm{ml}$ )-coated 48-well plates with RPMI medium containing $10 \%$ fetal bovine serum, L-glutamine, $10 \mathrm{U} / \mathrm{ml} \mathrm{IL}-2$ and $10 \mu \mathrm{g} / \mathrm{ml}$ anti-CD28. For Th2 cell priming, CD4 T cells were treated with $62.5 \mathrm{ng} / \mathrm{ml} \mathrm{IL-4}$ and $10 \mu \mathrm{g} / \mathrm{ml}$ anti-interferon (IFN) $\gamma$ for 5 days. To assess effects of PXRs on T cell activation, CD4 T cells were incubated with PCN at different doses. After 5 days, CD4 T cells were washed and resuspended in culture medium for another 2 days.

\section{Quantification of cytokines in murine skin}

Cytokine levels were measured in the skin of mice from the bleomycin experiments (six mice per group) by multiplex bead array technology (Bender MedSystems, Vienna, Austria) as described previously. ${ }^{17}$

\section{Statistical analysis}

All data are presented as median with IOR, and differences between the groups were tested by Mann-Whitney U nonparametric test.

\section{RESULTS}

PXR activation inhibits bleomycin-induced dermal fibrosis

To determine the antifibrotic potential of PXR activation, we first evaluated the effects of the PXR agonist PCN in the model of bleomycin-induced dermal fibrosis. In mice challenged with bleomycin, PCN effectively reduced dermal thickening by $85.9 \%(55.2-127.7 \%)(p=0.002)$ (figure 1A, B). Hydroxyproline content and myofibroblast counts showed similar results to scoring of dermal thickness (figure 1C, D), suggesting that PXR activation can effectively prevent experimental dermal fibrosis.

\section{PXR activation induces regression of established dermal fibrosis}

In a modified bleomycin model, we next investigated if PXR activation could also induce regression of established fibrosis. Starting PCN treatment after fibrosis had been established, we observed that it reduced dermal thickening and myofibroblast counts to below baseline levels, as represented by mice challenged with bleomycin for 3 weeks followed by $\mathrm{NaCl}$ for 3 weeks (figure 2A-C). Thus, PXR activation was effective in both preventing development of dermal fibrosis and reversing established dermal fibrosis.

\section{Inhibition of bleomycin-induced dermal fibrosis is mediated by} decreased TGF $\beta$ signalling

As in human SSc, TGF $\beta$ is a core pathway for fibroblast activation in bleomycin-induced dermal fibrosis. We therefore evaluated the inhibitory effects of PXR activation on TGF $\beta$ signalling in the bleomycin model by determining nuclear levels of phosphorylated smad2 and $\operatorname{smad} 3$ ( $\mathrm{p}-\mathrm{smad} 2 / 3)$, central downstream mediators of activated TGF $\beta$ signalling. Activation of PXR by PCN effectively inhibited the bleomycin-induced increase in nuclear $\mathrm{p}$-smad2/3 (figure $3 \mathrm{~A}$ ).

The antifibrotic effects of PXR activationare mediated by T cells We wondered if PXR mediates its antifibrotic effects directly on fibroblasts. We observed that PXR is expressed in human skin and fibroblasts, but treatment of cultured dermal fibroblasts with PCN, even in high doses, did not reduce the basal or the TGF $\beta$-induced colla1 mRNA levels or collagen release (data not shown).
Th2 cells are an important source of profibrotic cytokines in SSc, including IL-4 and IL-13. Since IL-4 and IL-13 released by Th2 cells can potently induce TGF $\beta$ signalling, ${ }^{12}$ we hypothesised that these cells may be the key to the antifibrotic effects of PXR. To test this hypothesis, we isolated murine CD4 T cells, induced a Th2 response, and treated cells with PCN. We found that PXR activation significantly reduced expression of the profibrotic Th2 cytokine, IL-13 (figure 3B). Under Th0 conditions, PCN did not induce significant changes in IL-13 expression (figure 3C). In contrast with IL-13, IL-4 expression did not change significantly under either Th0 or Th2 conditions (data not shown). Together, these data suggest that the antifibrotic effects of PXR activation on fibroblasts were indirectly mediated by inhibiting $\mathrm{T}$ cell activity and IL-13 release.

\section{PXR activation reduces dermal IL-13 levels}

To confirm these in vitro findings, we measured the levels of IL-13 in murine skin. We found a large decrease in IL-13 in the skin from bleomycin-challenged and $\mathrm{PCN}$-treated mice compared with mice receiving bleomycin and sham treatment (figure $3 \mathrm{D}$ ). IL-13 levels even declined below NaCl-challenged and shamtreated controls. Of note, we observed similar results for the Th2 cytokine IL-4 (see online supplementary figure S2), which may, on first glance, conflict with our in vitro findings that did not show significant effects on IL-4 synthesis in Th2 cells. The decrease in IL-4 levels on PCN treatment, however, may be due to additional effects of other inflammatory cell types in the complex in vivo model. Together, our results suggest that the antifibrotic activity of PXR activation in experimental dermal fibrosis mainly depends on the release of IL-13.

\section{DISCUSSION}

In fibrotic disease, $\mathrm{T}$ cells play an important role in initiating and propagating tissue fibrosis. ${ }^{1} 2$ Perivascular inflammatory infiltrates, with $\mathrm{T}$ cells representing the major cell population, are characteristic features in lesional skin biopsy specimens from early stages of SSc. In fibrotic disease, the T cell response appears to be Th2-based. T cells polarised towards a Th2 phenotype secrete abundant IL-4 and IL-13, both of which are important profibrotic mediators. The profibrotic activities of IL-13 involve both direct fibroblast activation and indirect mechanisms due to stimulation of TGF.$^{4518}$ Of note, levels of IL-13 are increased in patients with SSc. ${ }^{19}$ Our data show that stimulation of PXR can block the release of IL-13 from activated $\mathrm{T}$ cells, which inhibits the development of dermal fibrosis in in vivo models.

The profibrotic effects of IL-13 are, at least in part, mediated via canonical TGF $\beta$ signalling, a core pathway of fibrosis. ${ }^{12}$ IL-13 induces expression of TGF $\beta{ }^{4}{ }^{5}$ which in turn stimulates phosphorylation and nuclear accumulation of smad2 and smad3. Herein, we demonstrated that PXR stimulation blocks the activation of canonical TGF $\beta$ signalling. The inhibitory effects of PXR stimulation on canonical TGF $\beta$ signalling were indirect, since PXR activation did not show significant effects on TGF $\beta$-induced collagen release from fibroblasts under various experimental conditions in vitro. In contrast, PXR activation effectively reduced the release of IL-13 from $\mathrm{T}$ cells in vitro and in bleomycin-challenged mice. In this context, a recent in vitro study provides further evidence that PXR activation inhibits T cell proliferation and activation. ${ }^{20}$ Thus, activation of PXR inhibits canonical TGF $\beta$ signalling in fibroblasts indirectly by decreasing the release of IL-13 from Th2 cells. Further studies are needed, however, to further elucidate the molecular pathways linking PXR to Th2 inhibition and decreased TGF $\beta$ signalling in fibrosis. 
A $\quad \mathrm{NaCl}+$ mock

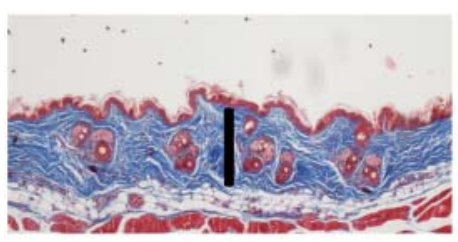

B

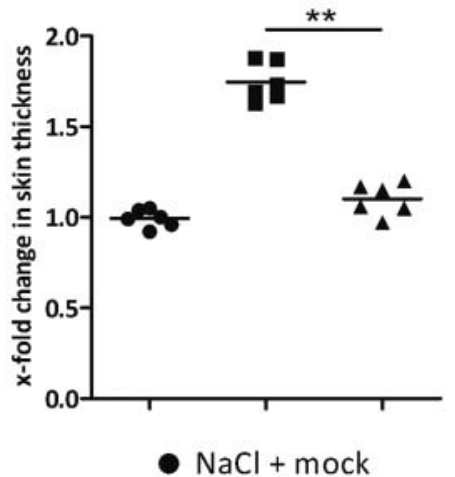

bleomycin + mock

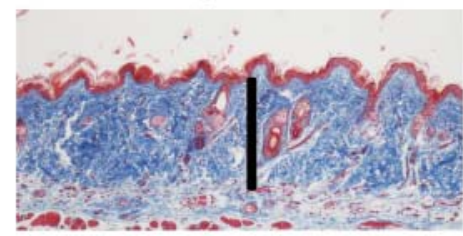

C

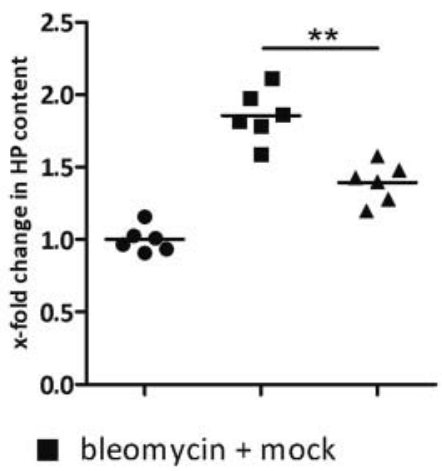

bleomycin + PCN

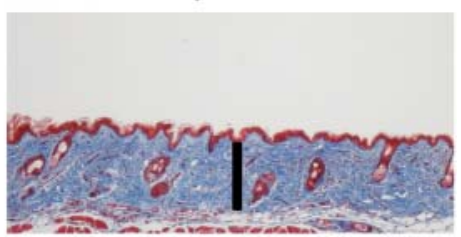

D

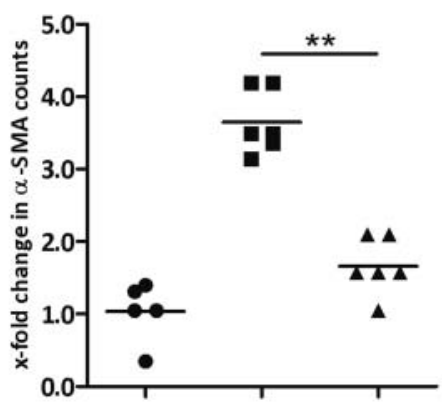

A bleomycin + PCN

Figure 1 Pregnane $X$ receptor activation prevents bleomycin-induced dermal fibrosis. Six-week-old DBA/2 mice were challenged with bleomycin

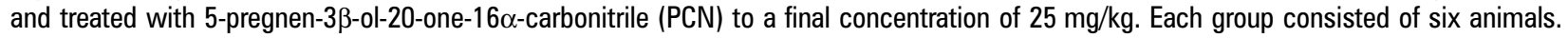
Quantitative analyses are presented as $\mathrm{x}$-fold change to the $\mathrm{NaCl}$-challenged, mock-treated controls. (A) Representative trichrome stains with collagens staining in blue. (B) Skin thickening as assessed with H\&E staining. (C) Hydroxyproline (HP) content of the murine skin. (D) Counts of $\alpha$-smooth muscle actin $\left(\alpha\right.$-SMA)-positive, dermal fibroblasts. w, weeks. $p$ Values are expressed as follows: ${ }^{* *} 0.01>p>0.001$. This figure is only reproduced in colour in the online version.

A

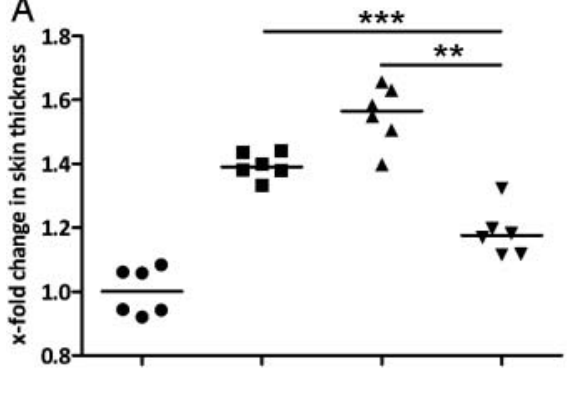

- $\mathrm{NaCl} 6 \mathrm{w} . /$ mock $6 \mathrm{w}$.

- bleomycin $6 \mathrm{w} . /$ mock $6 \mathrm{w}$.
B

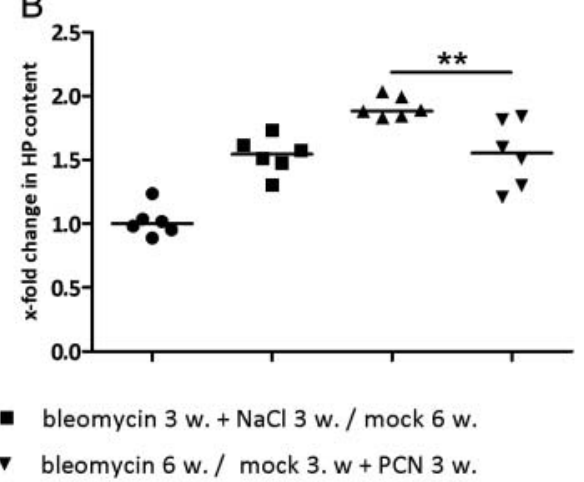

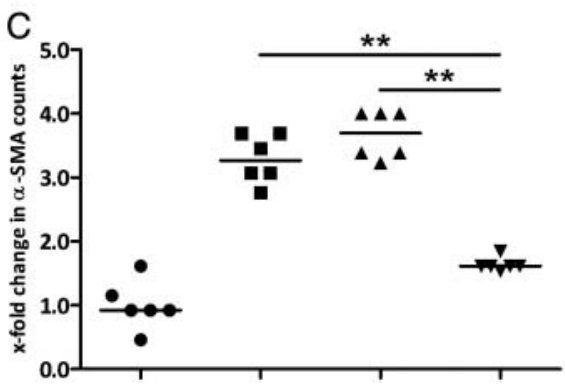

Figure 2 Pregnane $X$ receptor activation induces regression of established bleomycin-induced dermal fibrosis. Four-week-old DBA/2 mice were challenged with bleomycin and treated with 5-pregnen-3 $\beta$-ol-20-one-16 $\alpha$-carbonitrile (PCN) to a final concentration of $25 \mathrm{mg} / \mathrm{kg}$. Each group consisted of six animals. Quantitative analyses are presented as x-fold changes to the NaCl-challenged, mock-treated controls. (A) Skin thickening as assessed with H\&E staining. (B) Hydroxyproline (HP) content of the murine skin. (C) Counts of $\alpha$-smooth muscle actin ( $\alpha$-SMA)-positive, dermal fibroblasts. p Values are expressed as follows: ${ }^{* *} 0.01>p>0.001 ;{ }^{* * *} p<0.001$. 
A

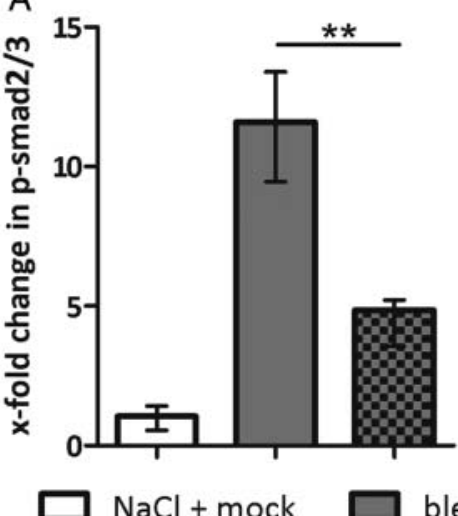

D

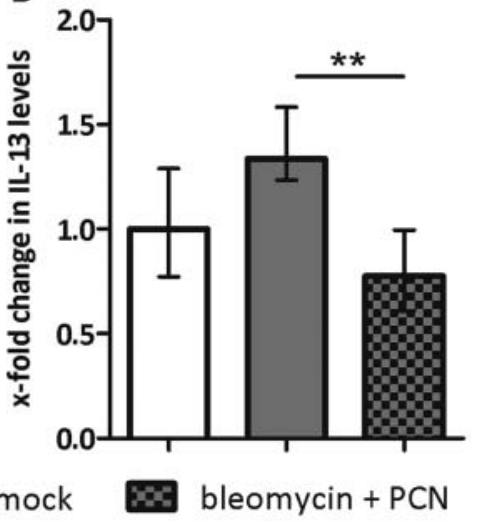

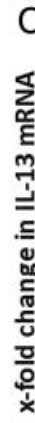

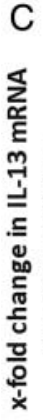

1.57
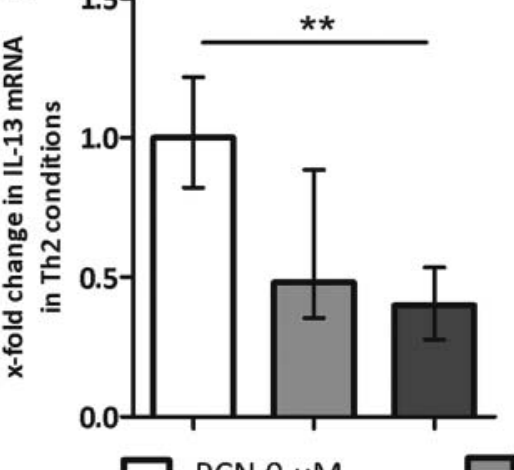

leomycin + mock

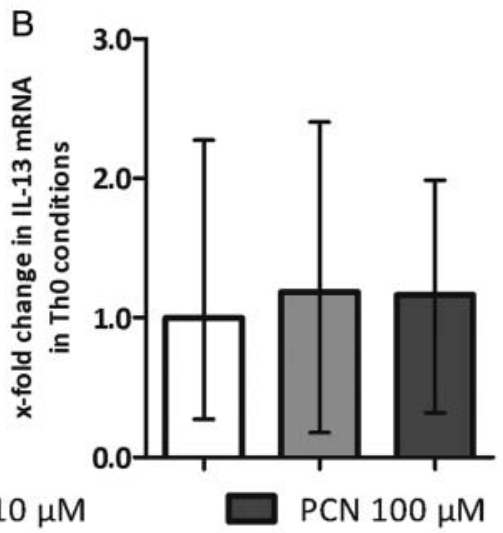

Figure 3 Pregnane $X$ receptor activation inhibits canonical transforming growth factor (TGF) $\beta$ signalling in murine skin by decreasing the release of interleukin (IL)-13. (A) Levels of phosphorylated smad 2 and 3 in the skin of bleomycin-challenged and 5-pregnen-3 $\beta$-ol-20-one-16 $\alpha$-carbonitrile (PCN)-treated mice (prevention model) as assessed by immunohistochemstry. The groups consisted of six animals each. Results are presented as $x$-fold change from the NaCl-challenged, mock-treated controls. (B) IL-13 mRNA levels in CD4 T cells under Th2 conditions on treatment with PCN at different doses. Results are expressed as x-fold changes to the non-treated T cells. (C) IL-13 mRNA levels in CD4 T cells under Th0 conditions on treatment with PCN at different doses. Results are expressed as x-fold changes to the non-treated T cells. (D) IL-13 levels in the skin of bleomycin-challenged and PCN-treated mice (prevention model) as assessed by multiplex bead array technology. The groups consisted of six animals each. Results are presented as $x$-fold change to the NaCl-challenged, mock-treated controls. $p$ Values are expressed as follows: ${ }^{* *} 0.01>p>0.001$.

In summary, we demonstrate, for the first time, antifibrotic effects of the nuclear receptor PXR. Activation of PXR interferes with IL-13 release from Th2 cells, which leads to decreased TGF $\beta$ signalling and reduced fibroblast activation and collagen release. These findings suggest that activation of PXR might be a novel antifibrotic approach in particular for inflammatory stages of SSc and other fibrotic diseases.

Acknowledgements We thank Madeleine Demleitner, Verena Wäsch, Stefan Fritz and Christine Schnabel for excellent technical assistance.

Contributors Study design: $C B, A S$ and JHWD. Data acquisition: $C B, A S, A D, C D$, HR, LM and JL. Interpretation: CB, HS-K, OD, GS and JHWD. Preparation of the manuscript: CB, HSK, JL, OD, GS and JHWD.

Competing interests $\mathrm{OD}$ has consultancy relationships and/or has received research funding from Actelion, Pfizer, Ergonex, BMS, Sanofi-Aventis, United BioSource Corporation, medac, Biovitrium, Boehringer Ingelheim, Novartis, 4D Science and Active Biotec in the area of potential treatments of scleroderma. JHWD has consultancy relationships and/or has received research funding from Actelion, Pfizer, Ergonex, BMS, Celgene, Bayer Pharma, Boehringer Ingelheim, JB Therapeutics, Sanofi-Aventis, Novartis, Array Biopharma and Active Biotec in the area of potential treatments of scleroderma and is stock owner of $4 \mathrm{D}$ Science $\mathrm{GmbH}$.

Funding Grant J29 and Grant A40 from the Interdisciplinary Center of Clinical Research (IZKF) in Erlangen; grants from the German Research Foundation (Grants DI 1537/1-1, DI 1537/2-1, DI 1537/4-1, DI 1537/5-1, BE 5191/1-1, AK 144/1-1 and
SCHE 1583/7-1); Career Support Award of Medicine from the Ernst Jung Foundation; and Grant 10 from Imprinting of the pathogenic memory for rheumatic inflammation (IMPAM) network supported by the German Federal Ministry of Education and Research.

Provenance and peer review Not commissioned; externally peer reviewed.

\section{REFERENCES}

1. Gabrielli A, Avvedimento EV, Krieg T. Scleroderma. N Engl J Med 2009; 360:1989-2003

2. Varga J, Abraham D. Systemic sclerosis: a prototypic multisystem fibrotic disorder. $J$ Clin Invest 2007;117:557-67.

3. Wynn TA, Ramalingam TR. Mechanisms of fibrosis: therapeutic translation for fibrotic disease. Nat Med 2012;18:1028-40.

4. Jinnin $\mathbf{M}, \mathrm{lhn} \mathrm{H}$, Yamane $\mathrm{K}$, et al. Interleukin-13 stimulates the transcription of the human alpha2(I) collagen gene in human dermal fibroblasts. J Biol Chem 2004:279:41783-91.

5. Lee CG, Homer RJ, Zhu Z, et al. Interleukin-13 induces tissue fibrosis by selectively stimulating and activating transforming growth factor beta(1). J Exp Med 2001;194:809-21.

6. di Masi A, De Marinis E, Ascenzi P, et al. Nuclear receptors CAR and PXR molecular, functional, and biomedical aspects. Mol Aspects Med 2009;30:297-343.

7. Haughton EL, Tucker SJ, Marek $\mathrm{CJ}$, et al. Pregnane $\mathrm{X}$ receptor activators inhibit human hepatic stellate cell transdifferentiation in vitro. Gastroenterology 2006:131:194-209 
8. Marek CJ, Tucker SJ, Konstantinou DK, et al. Pregnenolone-16alpha-carbonitrile inhibits rodent liver fibrogenesis via PXR (pregnane $X$ receptor)-dependent and PXR-independent mechanisms. Biochem J 2005;387:601-8.

9. Shah YM, Ma X, Morimura K, et al. Pregnane X receptor activation ameliorates DSS-induced inflammatory bowel disease via inhibition of NF-kappaB target gene expression. Am J Physiol Gastrointest Liver Physiol 2007;292:G1114-22.

10. Wang $\mathbf{H}$, Venkatesh $\mathrm{M}$, Li $\mathrm{H}$, et al. Pregnane $\mathrm{X}$ receptor activation induces FGF19-dependent tumor aggressiveness in humans and mice. J Clin Invest 2011; 121:3220-32

11. Kliewer SA, Moore JT, Wade L, et al. An orphan nuclear receptor activated by pregnanes defines a novel steroid signaling pathway. Cell 1998;92:73-82.

12. Akhmetshina A, Palumbo K, Dees $\mathrm{C}$, et al. Activation of canonical Wnt signalling is required for TGF-beta-mediated fibrosis. Nat Commun 2012;3:735.

13. Dees C, Akhmetshina A, Zerr $\mathrm{P}$, et al. Platelet-derived serotonin links vascular disease and tissue fibrosis. J Exp Med 2011;208:961-72.
14. Beyer C, Schramm A, Akhmetshina A, et al. beta-catenin is a central mediator of pro-fibrotic Wnt signaling in systemic sclerosis. Ann Rheum Dis 2012;71:761-7.

15. Beyer C, Reich N, Schindler SC, et al. Stimulation of soluble guanylate cyclase reduces experimental dermal fibrosis. Ann Rheum Dis 2012;71:1019-26.

16. Beyer C, Schett G, Distler 0, et al. Animal models of systemic sclerosis: prospects and limitations. Arthritis Rheum 2010;62:2831-44.

17. Avouac J, Furnrohr BG, Tomcik M, et al. Inactivation of the transcription factor STAT-4 prevents inflammation-driven fibrosis in animal models of systemic sclerosis. Arthritis Rheum 2011;63:800-9.

18. Kaviratne $\mathbf{M}$, Hesse M, Leusink M, et al. IL-13 activates a mechanism of tissue fibrosis that is completely TGF-beta independent. J Immunol 2004;173:4020-9.

19. Hasegawa M, Fujimoto M, Kikuchi K, et al. Elevated serum levels of interleukin 4 (IL-4), IL-10, and IL-13 in patients with systemic sclerosis. J Rheumatol 1997;24:328-32.

20. Dubrac S, Elentner A, Ebner $\mathrm{S}$, et al. Modulation of T lymphocyte function by the pregnane $X$ receptor. J Immunol 2010;184:2949-57. 


\section{$\triangle R D$ Activation of pregnane $X$ receptor inhibits experimental dermal fibrosis}

Christian Beyer, Alla Skapenko, Alfiya Distler, Clara Dees, Helena Reichert, Louis Munoz, Jan Leipe, Hendrik Schulze-Koops, Oliver Distler, Georg Schett and Jörg H W Distler

Ann Rheum Dis 2013 72: 621-625 originally published online January 4, 2013

doi: 10.1136/annrheumdis-2012-202476

Updated information and services can be found at:

http://ard.bmj.com/content/72/4/621

These include:

Supplementary Material

References

Email alerting service
Supplementary material can be found at:

http://ard.bmj.com/content/suppl/2013/01/04/annrheumdis-2012-2024 76.DC1.html

This article cites 20 articles, 8 of which you can access for free at: http://ard.bmj.com/content/72/4/621\#BIBL

Receive free email alerts when new articles cite this article. Sign up in the box at the top right corner of the online article.

Topic Articles on similar topics can be found in the following collections Collections Immunology (including allergy) (4412)

\section{Notes}

To request permissions go to:

http://group.bmj.com/group/rights-licensing/permissions

To order reprints go to:

http://journals.bmj.com/cgi/reprintform

To subscribe to BMJ go to:

http://group.bmj.com/subscribe/ 